\title{
Effect of Inhibitor based on Emulsion on Mild Steel Corrosion in Acid Environment
}

\author{
Juan Du ${ }^{1}$, Yue Liu ${ }^{1}$, Pingli Liu ${ }^{1, *}$, Yigang Liu', Shang Gao ${ }^{2}$, Liping Zhang ${ }^{2}$ \\ ${ }^{1}$ State Key Laboratory of Oil \& Gas Reservoir Geology and Exploitation Engineering, Southwest \\ Petroleum University, Chengdu, Sichuan, 610500, China \\ ${ }^{2}$ CNOOC China Co. Ltd. Tianjin branch, Tianjin, 300000, China \\ *E-mail: liupingli@swpu.edu.cn
}

doi: $10.20964 / 2019.05 .18$

Received: 19 November 2018 / Accepted: 24 February 2019 / Published: 10 April 2019

\begin{abstract}
An inhibitor based on emulsion was prepared by anti-corrosion substances, crude oil and emulsifier in this paper. The inhibition behavior of this inhibitor based on emulsion on $\mathrm{N} 80$ steel in $10 \% \mathrm{HCl}+$ $4 \% \mathrm{HBF}_{4}$ solution was investigated by electrochemical measurements and soaking experiments. Results of electrochemical impedance spectroscopy and surface analysis studies indicated that the inhibitor based on emulsion can effectively inhibit the corrosion reaction by forming an adsorption layer function as a barrier. Polarization curves indicated that it is mixed type inhibitor which can reduce anodic dissolution and cathodic hydrogen evolution reactions simultaneously. Experimental results indicated that the inhibitor based on emulsion has better anti-corrosion performance than that of composite inhibitor without crude oil and emulsifier even though with smaller application concentration.
\end{abstract}

Keywords: inhibitor based on emulsion, $\mathrm{N} 80$ steel, $10 \% \mathrm{HCl}$ and $4 \% \mathrm{HBF}_{4}$ solution, weight loss method, electrochemical method

\section{$\underline{\text { FULL TEXT }}$}

(C) 2019 The Authors. Published by ESG (www.electrochemsci.org). This article is an open access article distributed under the terms and conditions of the Creative Commons Attribution license (http://creativecommons.org/licenses/by/4.0/). 